\title{
Working in a digital world; new leadership practices for the development of a digital library workforce
}

\author{
Johann van Reenen \\ MSc, AHIP, M.Dip.Lib.Sci. \\ University of New Mexico, UNM Libraries, and the Ibero-American Science \\ $\mathcal{B}$ Technology Education Consortium, Albuquerque, NM, USA \\ E-mail: jreenen@unm.edu
}

\section{Resumo}

Os progressos da biblioteca digital são parte de um movimento global em muitos setores da sociedade rumo ao trabalho virtual e serviços eletrônicos disponibilizados pelos avanços da tecnologia da informação. Este ambiente requer novas atitudes e habilidades na força de trabalho e, por isso, líderes que compreendam as mudanças por que passa a economia da informação e como tratar e desenvolver tal força de trabalho. Este artigo explora métodos para desenvolver os recursos humanos e estimular a criatividade para capitalizar o imenso potencial das bibliotecas digitais no sentido de educar e fortalecer a mudança social. Há uma falta de trabalhadores tecnicamente habilitados e, acima de tudo, de inovadores. Retenção e recrutamento são um dos maiores obstáculos ao avanço dos serviços da biblioteca digital e aos produtos de informação.

\section{Palavras-chave}

Bublioteca digital; Intercâmbio de informação.

\section{Working in a digital world; new leadership practices for the development of a digital library workforce}

\begin{abstract}
Digital library developments are part of a global move in many sectors of society toward virtual work and electronic services made possible by the advances in information technology. This environment requires new attitudes and skills in the workforce and therefore leaders who understand the global changes underlying the new information economy and how to lead and develop such a workforce. This article explores ways to develop human resources and stimulate creativity to capitalize on the immense potential of digital libraries to educate and empower social change. There is a shortage of technically skilled workers and even more so of innovators. Retention and recruitment is one of the greatest obstacles to developing digital library services and information products.
\end{abstract}

Keywords

Digital library; Information interchange.

\section{INTRODUCTION}

Access to knowledge is probably the most critical component for success in the evolving electronic global economy. Funding agencies and politicians are expecting academic and public libraries to deliver information services that make their organizations and countries competitive. Traditional library functions have been changing during the last decade to accommodate these expectations and now co-exist with many new and innovative digital library functions. The potential for a particular library to keep up or accelerate the rate of change is directly related to the percentage of library workers who have taken up the required new roles in spite of traditional education and experiences. Most leaders of digital library projects find that it is not the changes driven by new technologies and new demands placed on libraries that are holding their organizations back but the lack of this new type of worker. New leadership insights and practices are called for. Leaders need to understand the concepts and management philosophies that drive innovation and success in the information era. It is critical to allow less control and more creativity and risk taking in everyday business.

\section{Digital workers for the $21^{\text {st }}$ Century}

The nature of the workplace, the worker, and the work has been radically altered by the shift from an industrial to information age. Workers in the Industrial Era were usually located in urban factories doing repetitive and routine work, often on an assembly line. Productive workers were seen as those who were reliable and passive and good at manual work.

Workers in the Information Era, however, can work anywhere with electronic connectivity and can work flexible time schedules. They are required to be innovative, learn quickly and continuously, work collaboratively, and be comfortable with experimentation and risk taking. They require less supervision and more coaching and vision from their leadership. 


\section{Working in a digital world; new leadership practices for the development of a digital library workforce}

Organizations who want to succeed in the $21^{\text {st }}$ Century must adjust to new leadership and management realities brought about by six primary characteristics of the new century (Tetenbaum 1998):

1. Technology: The infomedia industries (computers, communications, and consumer electronics) are now one of the largest sectors of the global economy. The new technologies increase efficiency, productivity, speed of production, and consumer power. This creates an attractor condition (Friedman, 1998) that leads still more people to adopt technology as IT becomes increasingly more affordable.

2. Globalization: Increasingly large numbers of people all over the world are interconnected in the flow of information, money, or goods; thus interdependence is growing.

3. Competition: Globalization and technology have led businesses to compete fiercely for a worldwide market share. Small companies can out-compete large, established companies based on flexibility and technological innovation.

4. Change: The changes we are currently experiencing are discontinuous and happening at an ever faster rate. Organizations must be sufficiently agile to be instantly re-configurable to meet constantly changing conditions. The disequilibrium created by this type of change is unprecedented in our history. The environmental changes occurring are so different from earlier conditions that organizations are disconnected from experiences that informed past decisions and it becomes less and less feasible to learn from past experience and tradition.

5. Speed: Increased technological speed is matched in business by fast paced product life cycles and escalating competition.

6. Complexity and Paradox: Paradoxes will be ubiquitous in the new millennium and will present a significant challenge to managers. However, it also offers opportunities to improvise and innovate that we will be exploring in this article.

In combination, these factors contribute to the complex and unpredictable nature of the current workplace where these technological developments often seems to force chaotic change. Although some of these will affect all industrial and social sectors, their effect will be felt most by knowledge workers and information-based endeavors.

\section{Understanding natural systems}

The incorporation of ideas derived from Chaos and Complexity theories into management thinking is a significant new trend. Such theories enable us to understand why the power of new technology and electronic networks can unexpectedly and fundamentally change the way we work.

In the past it was reasonably easy for organizations to engage in strategic planning, setting new mandates and visions, and finding the people to act on these. When the environment is fairly predictable and there is a fair amount of agreement among people in the organization about future needs and challenges it is possible to plan but when uncertainty escalates and there is therefore less internal agreement, organizations functions in what Stacey $(1991,1992)$ calls the "creativity space" at the edge of chaos.

Experts say that adaptation is at the heart of competing on the edge. Organizations must become complex adaptive systems (CAS) that resemble the nonlinear feedback systems one can find so abundantly in nature. An important characteristic of CAS is that they are composed of autonomous agents whose interactions with each other produce the emergent structures that form the unique properties of a system. Such systems are based on a few rules and much randomness that create unexpectedly complex and sometimes useful results. The flocking behavior of geese - i.e. flying in a $\mathrm{V}$-formation illustrates this concept. They appear to follow a few simple rules; don't bump into each other; match up with the speed of other geese flying nearby; replace the lead goose when it gets tired; and always remain with the group. Yet a complex and efficient flying pattern emerges from these few rules. The group relies on constant feedback and adaptation to achieve its goal of remaining resilient in the face of changing circumstances such as encountering geographic or weather obstacles.

The lesson here is that rather than stifling chaos, managers should allow it to flourish. They also must ensure that the work environment encourages interaction and creativity. In nibble organizations leaders should not provide answers but create the flexibility that encourage employees to come up with the solutions. In a complex turbulent environment, the mechanistic, authoritarian and hierarchical decision-making process is too slow and too cumbersome to react to the situation. Employees at every level of the organization need to bring their intelligence and capacity to their work and to make 


\section{Johann van Reenen}

decisions quickly. Any or every employee may hold a piece of the puzzle that is critical to completing the picture. Three examples of natural systems based on the paradox of rules and randomness are discussed below.

\section{Silicon Valley}

Most readers are familiar with the phenomenal success of Silicon Valley, but how was it "created or managed"? The existence of Silicon Valley can be attributed largely to the intersection of distinguished research centers at Stanford and the University of California at Berkeley and the availability of skilled labor. These are the "rules". While Silicon Valley is unique, other high-tech economic areas have emerged in Austin, Texas, the Triangle Research Center of North Carolina, and the Boston area's Route 128. Their emergence shares a commonality with Silicon Valley in that they, too, arose in areas providing excellent educational institutions and skilled labor. Thus, while these centers differ from one another, clear patterns can be detected: The availability of advanced technology, which attracts electronics manufacturers who, in turn, attracts component suppliers and support companies. The "rules" or common features in these patterns of geographical economic development would seem to suggest that they can be deliberately created, yet when governments attempt to artificially create these geographic concentrations, they often fail (Eisenhardt \& Brown 1998), this is the "randomness" of chaotic systems. Chaos is self-organizing and no individual or organization was in charge of creating a high-tech industry in Silicon Valley, it "emerged" based on some natural rules and capitalizing on randomness. It is a prime example of how spontaneous self-organizing systems produce extraordinary outcomes out of chaos.

\section{The Global Internet Economy}

The Internet and its global marketplaces represent another type of self-organizing system. No one is really in charge of the Internet, which is still in the process of evolving. Nor is any particular country or organization in charge of global markets, yet considerable coherence emerges from millions of independent, but connected, decisions. The success of both these developments is undeniable. Managing such a massive and unpredictable explosion of capacity and creativity would have been beyond the skills of even the most astute and capable executives. The Internet had to be self-managed. Malone \& Laubacher (1998) speculate that "The Internet is the greatest model of a network organization that has yet emerged, and it reveals a startling truth: in an e-lance economy, the role of the traditional business manager changes dramatically and sometimes disappears completely."

\section{The LINUX operating system}

The almost spontaneous development of the Linux version of the UNIX operating system, is an elegant illustration of this point. Linux software was developed as free-ware. It attracted the attention of more and more programmers over time who contributed their own ideas and improvements. The Linux community grew steadily, soon encompassing thousands of people around the world, all sharing their work freely with one another. Soon, this loose, informal group, working without managers and connected mainly through the Internet, had turned Linux into one of the best versions of UNIX ever created (Malone \& Laubacher 1998).

How would such a software development project have been organized by one of today's major software companies or in our own organizations? Malone \& Laubacher (1998) speculate that "decisions and funds would have been filtered through layers of managers. Formal teams of programmers, quality assurance testers, and technical writers would have been established and assigned tasks. Customer surveys and focus groups would have been conducted, their findings documented in thick reports. There would have been budgets, milestones, deadlines, status meetings, performance reviews, [and] approvals. There would have been turf wars, burnouts, overruns, [and] delays. The project would have cost an enormous amount of money, taken longer to complete, and quite possibly produced a system less valuable to users than Linux."

They suggest that the Linux community, a temporary, self-managed gathering of diverse individuals engaged in a common task, is a model for a new kind of business organization that could form the basis for a new kind of economy.

\section{The Future of Information and Knowledge Management}

"All aspects of work and business -all products, all activities, all methods - have an information structure at their core that has long been hidden, just like the genetic codes of plants." (Maruca, 1999)

Successful organizations are beginning to understand and organize internal (company) and external information and manipulate its structure for economic advantage. According to Maruca (1999), traditional companies share 
characteristics with traditional farmers. Farmers followed the same farming practices for centuries by applying improved methods of cultivation incrementally. This served them well until genetic engineering became feasible. Genetic engineers changed the nature of corn, soybeans, orange trees, and other crops. They increased yields by $300 \%$, as well as resistance to disease. Eventually they found ways to improve other aspects such as taste and color. They did this at the genetic level by manipulating the information within the seeds. Farmers can ignore the genetic engineers and go on using all the old, established methods, but they would find it more and more difficult to compete in a marketplace where others are using these advances. The benefits of genetic engineering are too revolutionary to ignore. The greatest value in business will ultimately reside in the information within business methods rather than their outputs. As Maruca (1999) pointed out "There is, after all, more value in manipulating the information structure of the gene than there is in being a farmer. There is more value in being a user of electricity than in being a producer of electricity. There is more value in Microsoft's intellectual property than in its products. Any business that thinks it is somehow insulated from the information revolution isn't likely to succeed in tomorrow's economy."

Dell $^{\mathrm{TM}}$ Computers provide another example of the importance of utilizing the information imbedded in processes. Dell ${ }^{\mathrm{TM}}$ sold about 70,000 computers in 2001. Whenever a computer is sold, a signal is propagated through the Del system back to the suppliers. Thus the suppliers know immediately when and what materials to deliver to Dell factories so that the orders can be filled. Michael Dell says: "So you get out of this business of having inventory problems. You don't have any inventory, what you have is information, and information is a lot easier to manage than inventory" (Anonymous, 2001).

Managing your organization's information to improve organizational learning and success is knowledge management. We generally focus on the qualities of information that are relatively easy to manage, such as its capacity to be stored, processed, and transferred in vast quantities. Libraries do this very well! Information is treated as an entity compatible with established organizational systems and channels of communication. However, information by itself has little value, much like an isolated fact; it is only when information interacts with other information that it acquires significance and value. Organizations that understand this generally have formalized ways for transforming information into useful knowledge. However, informal networks, often personal rather than institutional in nature, have proved most effective (Maas, 1998). The managerial qualities of experience and judgment, not more systems, his study suggests, are what enable organizations to make effective use of information gathered serendipitously.

The increasing importance of intellectual assets has compelled executives to examine the knowledge underlying their businesses and how it is used. Some companies automate knowledge management; others rely on their people to share knowledge through more traditional means. The demands to build effective organizational learning processes in distributed environments are likely to accelerate especially when combined with the rapid developments in information technology.

\section{New Leadership Requirements in the Digital Environment}

We can begin to extrapolate the new requirements for leadership in the emerging electronic workplace from the above discussions and thus for digital library leaders.

- Leaders give up control to achieve innovation

"So, when you insist on your vision, when you try to stick to your blueprint, when you cling with so much determination to control, are you destroying the capacity of your organization for complex learning? " (Stacey 1996 b).

- Leaders foster Communication and build Relationships

"In this new world span-of-control mentalities must give way to span-of-communication mentalities."(Leinberger and Tucker, 1991)

Leaders communicate obsessively and share intelligence, information and meaning directly to employees. They create opportunities for discussion and use every communications technology available to the organization. This will encourage two critical components of creativity: posing questions and involving unlikely partners in conversations, discussions and meetings.

Leaders need to communicate both formally and informally to forge relationships and knowledge networks. Research suggests that it is a mistake to think about knowledge networks only in terms of technology. It is important to study the web of relationships that exist among the units in an organization. The way a unit is linked to others has a dramatic effect on its performance 
(Cliffe 1998). The difference in performance can largely be traced to two organizational factors: a unit's centrality in the corporate network and the types of relationships it maintains with other units. The relationship between two units should be tailored to the type of knowledge that needs to flow between them. Digital librarians are uniquely positioned to do this.

\section{Leaders develop resilient employees who can absorb future shocks}

We have discussed the need for interactivity and sharing intelligence but to manage the unknown future an organization must have the capacity to absorb shocks in times of uncertainty and chaos. All information-based organizations such as libraries and universities are experiencing such times. Employees will need the following characteristics to become more resilient: be focused, organized, proactive, and must develop confidence in their ability to deal with change. This is encouraged through training, building an understanding of the external world and global socio-economic changes, and by creating an organizational culture of continuous improvement.

- Leaders ensure effective decision making and encourage risk taking

Clearly, leaders must be able to manage the paradox of chaos and order as they juggle creativity and experimentation along with control and efficiency. In the evolving electronic workplaces, leaders must "push the envelope to survive, we live in a constant stream of tensions: balancing work with play, creativity with competition, complacency with outrageousness" (Tetenbaum, 1998). This means honing the decisionmaking skills at all levels of management. Decisionmaking is the most important job of any executive. It is also the toughest and riskiest because of the ways in which human psychology can sabotage decisions. Decision makers display a strong bias toward alternatives that perpetuate the status quo as you may know from your own experiences! These are called "decision making traps" by Hammond, et al (1998). In the electronic environment, especially when investing in information technology, many leaders and their management teams are treading new ground. Understanding and awareness of such traps are more necessary than ever
- Leaders integrate and synergize

Leaders must have the ability to integrate opposites. The challenge for managers and their teams is to create coexisting, highly differentiated as well as highly integrated organizations. Differentiating units is easy; achieving integration is not. Tushman \& O'Reilly (1999) stress that innovation (either incremental or discontinuous) stems from two component processes: those structures, people, incentives and cultures that promote creativity and those that facilitate implementation. The need for creativity must be balanced with the need for execution; they state that: "Organizations can sustain their competitive advantage by operating in multiple modes simultaneously - managing for short-term efficiency by emphasizing stability and control, and for long-term innovation by taking risks and learning by doing. Organizations that operate this way may be thought of as ambidextrous - hosting multiple, internally inconsistent architectures, competencies and cultures, with built-in capabilities for efficiency, consistency and reliability on the one hand, and experimentation, improvisation and luck on the other."

- Leaders encourage creativity and innovation

Today's leaders are challenged to create an environment that encourages unexpected advances and unleashes creativity in traditional organizations such as our universities and research establishments. The rest of our discussion focuses on this aspect of the new leader. There is a shortage of technically skilled workers and even more so of innovators. Retention and recruitment is one of the greatest obstacles to developing digital library services and information products.

\section{Strategies for creating the digital workplace and worker}

Telework:

Telework is driven by computers, email, voicemail and the Intemet and marks the transition from working in the industrial age to working in the information age.

The potential strategic and competitive advantages of the mobility and flexibility provided by virtual work environments are beginning to impact all types of enterprises.

More and more all work places are managing alternative work arrangements usually mixing virtual and non-virtual offices and activities. The number of telecommuters in the USA rose to 15.7 million in 1998, and then to an estimated 18 million in 1999 (Alexander 1999). 


\section{Working in a digital world; new leadership practices for the development of a digital library workforce}

Watever the advantages and challenges of virtual work and workers, this trend is here to stay and will impact leadership and the management of information workers.

Group Support Systems and Collaborative Technologies:

Computer-supported cooperative work (CSCW) holds great importance and promise for the new workplace and for society at large (Mills, 1999). Organizations will need to improve the ability of teams to work together through networks of computers.

Telecommuting and any form of electronic work require the correct tools. For the types of workers we discussed above that means having an array of reliable, portable tools which facilitate communication, organization, and performance. Such technology, however, is not only essential for telecommuters, but is also used by those working in the conventional office.

People who work together in cross-functional or even cross-organizational teams must quickly establish a work plan, divide up tasks, and determine means of coordination and self-regulation. Often team members work asynchronously, but their work must still be coordinated effectively.

Problem resolution, idea generation and innovation are enhanced when using group support systems. From a theoretical perspective, electronic communication can provide three components that may significantly change information exchange: parallelism, anonymity, and group memory. Parallelism is the ability of all members to exchange information simultaneously. This allows a group member to participate when he/she has an idea without having to wait their turn (Mills 1999). Anonymity allows even the most timid worker to participate on a level electronic playing field. It also encourages more risk taking and more outrageous but potentially useful ideas.

Group memory is the electronic capture of the group's work. This is then available for review by the group and others in future to stimulate new ideas and add to the value of organizational intellectual capital. All the members of a group thus have a common, shared memory that can be used during or after the meeting. One of the underlying assumptions of the impact of group memory on idea generation is that this feedback improves individual problem solving as well as electronic brainstorming in general (Satzinger et al 1999).
Virtual cross functional teams and skunk works:

How can we bring the startup mentality inside our large existing organizations and apply it to digital library projects?

By creating entrepreneurial units within the traditional organization from which the rest can learn. What Stepanek (1999) calls "rebel bands" and Tushman \& O'Reilly (1999) calls "skunk works" Such groups are relatively small, have loose decentralized product structures, experimental cultures, loose work processes, strong entrepreneurial and technical competencies and are relatively young and heterogeneous employees. Entrepreneurial units build new experience bases and knowledge systems; they generate the experiments, failures, and they create the variation from which possible dominant designs or technological discontinuities can emerge. The ambidextrous organizations referred to earlier, build in contradictions as they operate both for today and tomorrow. Tushman \& O'Reilly(1999) believes that management must protect and legitimize entrepreneurial units and keep them physically, culturally and structurally separate from the rest of the organization. There is good evidence that this "rebel culture" pushes decision-making deep into the organization and cut through layers of bureaucracy, resulting in the creation of even more innovative teams (Stepanek 1999).

Acquiring, growing, and keeping creative people:

Learning organizations are challenged to grow and keep creative people. Creative types design the software, Web pages, and special projects that convince people to use our services and continue using them. It is not advisable to manage creative people in traditional ways. Cook (1999) provided useful ideas for keeping and encouraging creative poeple:

1. Structure without control. It is better not to try to manage creative employees at all. It is more effective to motivate them through new leadership behaviors. They require more freedom, with the only structured provided through deadlines and guidance, rather than management techniques. "High-tech and artistic people don't accomplish anything without structure, but the structure needs to be primarily unknown to them and unconscious." (Cook 1999)

2. Forget the 9-to-5 work day. Creative people work on their own flexible schedule. 
3. Right brain and left brainworkers. Teams usually consist of right brain (creative), left brain (technical), and strategic (synapse) members. Although there are some inherent difficulties in getting creative and noncreative types to work together effectively, allowing employees' unique personalities to become apparent through such exercises help them to see the value of others.

\section{Feedback gets amplified}

Knowing how to give feedback is a crucial aspect to improve relationships between creatives and noncreatives. Because the creative process is such an intensely personal pursuit, improperly presented feedback can be extremely damaging. Therefore, it's necessary to help creatives articulate how they feel about the feedback they've been given. By setting clear expectations in the beginning, a manager can tie criticism back to the initial expectations and explain why certain aspects of the project don't work. Integrating peer reviews into the evaluation process generally provides greater credibility as most creative work is highly subjective.

\section{The creative career track}

Creative types generally do not make good managers and another career path needs to be developed for them. They must have assurances that they can rise high in the organization without being forced to manage people.

\section{Managing smarter people}

Non-technical people may have to manage technical people and may be perceived as less smart than their employees. However, leaders and managers need not be as technically proficient as those who work for them because their role is quite different. This should not be a stumbling block in hiring and keeping creatives.

\section{Job sculpting.}

Another strategy to keep new types of workers is to "sculpt" jobs specifically for them. Job sculpting is used as a competitive strategy by many electronic-based organizations but is more difficult in traditional libraries. It is the art of matching people to jobs that resonate with the activities that make them happy. Butler \& Waldroop (1999) says that managers need to listen more carefully when employees describe what they like and dislike about their jobs and talk about their deeply embedded life interests. They then work together to customize future work assignments. Employees stay at jobs only if the job matches their deeply embedded life interests
Systematic enhancement of creativity and innovation for digital library projects

I hope I have proved through the above discussion that there is a clear need to produce novel but appropriate ideas to solve digital library challenges and create "breakthrough" solutions for improving scholarly communication processes. Sullivan (2000) defines creativity and innovation thus:

"Creativity is the process of bringing a novel idea into existence. Innovation is the practical application of creative ideas."

He describes three key elements for a creative workplace:

- individuals who are willing to tap their creativity and express ideas

- an environment which supports creativity and innovation, i.e. risk taking, trust, openness, play, and humor

- allowing time for idea generation

- having the necessary resources (time, money, energy, learning)

There is a body of scientific literature that explores the ability of organizational processes to enhance creative thinking and innovation. A comparison of a number of these can be found in Andriopoulos and Lowe (2000) and I will be making frequent reference to this work. Their study was conducted on subjects working in organizations whose main business is creativity, thus some points may be overstated for organizations with large traditional process-based components. However, I believe their ideas are so important that they need to be discusses here in some detail and that they apply to creative work in all types of organizations, including libraries.

This section is written with the naturally creative person in mind and for teams whose main purpose is to solve problems through innovation, whether in a temporary or permanent capacity. Thus, when I refer to "employees", I mean those people identified for or assigned particularly to creative functions. There is clearly a need for employees in other parts of the organization to maintain and continually improve existing processes and functions. 
Putting it in practice:

- Perpetual Challenging.

Andriopoulos and Lowe (2000) provides one of the best theoretical frameworks for examining the formal and informal elements of creativity. They established that the grounded theory of "Perpetual Challenging" is a reliable and practically useful process for enhancing organization creativity. I am therefore providing a more detailed summary of this concept.

Perpetual Challenging (PC) refers to ways of encouraging creative and intelligent workers to achieve their full potential, to enhance 'employees' internal drive to perceive every project as a new creative challenge so that their individual contribution is maximized and an innovative solution can arise." (p.736).

PC comprise four processes for enhancing creativity: adventuring, overt confronting, portfolioing, and opportunizing. The authors' definitions follow below.

Adventuring is the process through which individuals are encouraged to explore uncertainty. This is achieved through experimentation, introspection and the making of scenarios. I explore the latter in greater detail later.

Overt confronting refers to "the deliberate [setting] of workrelated debates among employees ... so that their creative thinking is fully utilized" (p.737). They identify two types of confronting, conceptual and contextual. Conceptual confronting uses the constant questioning of external, internal, and each other's ideas. This creates healthy conflict and a better understanding of the underlying issues. Contextual confronting occurs when there are organizational pressure placed on employees by requiring them to work at ever higher levels of difficulty and against deadlines. They constantly confront new obstacles and learn continually from the projects and each other (see also related work by Senge, 1990 and 1999, in this field).

Portfolioing require that employees get involved in a diverse range of projects and with different project teams. It is an important creativity-building skill to work on multiple projects simultaneously. It also allows a group or individual to switch from project to project when they are temporarily at a loss for new ideas and to renew their creativity by working on something different.

Opportunizing refers to a process that allows employees to work on projects not only because it is required but because there are significant tangible benefits in it for them. There should be opportunities for financial rewards as well as recognition; "the ideal project is the one that has creative as well as financial opportunities" (p.738).

There are many other processes that have been used to stimulate the generation of creative ideas. Below I list more of these. It behooves organizations in the rapidly changing electronic environment to explore as many of these as possible.

- Exploiting uncertainty. This can be done by ensuring that each rational process has its irrational side. For instance, meetings should have an orderly part as well as a chaotic portion. Leaders should ensure that employees understand the value of the discussions and concepts from the previous sections, in particular ideas contained in the works of Stacey between 1991-1999 . According to Sternberg et al (1997) managers should allow "messiness" to exist and stresses that the uncertainty associated with creative projects must not be controlled just because of a need for orderliness in traditional settings. This is important advice for those planning digital library projects as part of traditional libraries.

- Electronic meeting and brainstorming systems are useful in generating ideas. Everyone in the meeting can "talk at once" by typing into his or her computer. The system then instantly distributes the contributions throughout the group. This means that participants do not lose track of their ideas while listening to other contributions, nor do they lose track of what others are saying while they are contributing-because all ideas become part of a real-time and permanent written record. Strong personalities can no longer dominate or sidetrack a meeting. Weaker personalities have equal access to the "floor." And because individuals provide input anonymously, participants evaluate each idea's merit independently from the personality of the person delivering it. Participants can float unconventional or unpopular ideas without evaluation apprehension.

More information on virtual collaboration can be found by visiting the web site of the Collaboratory for Research on Electronic Work at http://www.crew.umich.edu/.

- "Scenario planning" is a process that enables us to visualize a range of opportunities through analyzing trends and competitive intelligence. The process facilitates a break with traditional thinking and encourages creative "what if" thinking. Arranging trends in some form of a logical "story" can facilitate comprehension and relevancy. This brings to the surface unspoken assumptions about the future, challenges mental models, and frequently unblocks creativity and resourcefulness. (Tucker 1999) 
- Thinking exercises can be employed when work groups are stuck for new ideas. The Six Hats method is a well known thinking tool kit developed by Edward de Bono, a man many regard as the authority in teaching thinking as a skill.

- The arrangement of office spaces that, for instance, allow frequent interactions, the use of unstructured meetings and unusual meeting locations, and other non-traditional work arrangements also stimulate creativity and help foster a new organizational culture.

\section{CONCLUSION}

Leaders in the information economy need to understand the concepts and management philosophies that drive innovation and success in this environment. It is critical to allow less control and more creativity and risk taking in everyday business. The demands to build effective organizational learning processes in distributed environments are likely to accelerate especially when combined with the rapid developments in information technology. The role of leaders in this kind of world are not to direct others in what to do but to establish the conditions in which workers can realize their own creativity on a much larger scale than is currently the case.

There is a need to adjust library operations through its leadership to operate effectively in a digital global environment. Digital library leaders are challenged to create an environment that encourages unexpected advances and unleashes creativity in traditional organizations such as our universities and research establishments. We must shift our focus (Sanders 1998):

- "from microscopic, local views with a focus on the marketplace to global views, with focus on the environment

- from a model wherein structure creates process to a model wherein the interactions within a system create self-organizing structures

- from a focus on organizational pathology to a focus on organizational potential

- from paying attention to policies and procedures that are fixed and inflexible to paying attention to perking information and emerging events

- from planning steered by strategic-planning committee or consultants to whole-system input into planning process
- from a focus on quantitative data to visual thinking in the bigpicture context

- from seeing change as a threat to seeing change as an opportunity

- from leadership being responsible for success to everyone being responsible for success."

The modern leader has four roles - direction-setter, change agent, communicator, and mentor. Nanus (1997) believes that "these provide the answer to all the turbulence, exploding uncertainty, change, and complexity" that face leaders in the global economy and the rapidly changing electronic environment.

The development of digital library services and products will require a realignment of organizational priorities, reallocation of resources, and the creation of a new cadre of workers. More importantly, it requires committed leadership and champions within the organization who can make a compelling case for the benefits of digital library services in managing organizational knowledge, creating innovation, and living with the accompanying uncertainty and risk.

\section{REFERENCES}

ALEXANDER, A. The virtual office: virtually everywhere. Accounting Technology, n. 5, p. 50-54, 1999.

ANDRIOPOULOS, C.; LOWE, A. Enhancing organizational creativity: the process of perpetual challenging. Management Decision, n. 38, p. 734-742, 2000.

BUTLER, T.; WALDROOP, J. Job sculpting: the art of retaining your best people. Harvard Business Review, n. 77, p. 144-152, 1999.

CLIFFE, S. Knowledge management: the well-connected business. Harvard Business Review, n. 76, p. 17-21, 1998.

COOK, J. Creative solutions: managing mavericks and mad geniuses. Office Systems, n. 16, p. 37-41, 1999.

EISENHARDT, K.; BROWN, S. Competing on the edge: strategy as structured chaos. Boston : Harvard Business School, 1998.

HAMMOND, J.S.; KEENEY, R. L.; RAIFFA, H. The hidden traps in decision making. Harvard Business Review, n. 76, p. 47-58, 1998.

LEINBERGER, P.; TUCKER, B. The new individualists. New York : Harper Collins, 1991.

MAAS, J. Information for innovation: managing change from an information perspective. Sloan Management Review, n. 40, p. 105-106, 1998.

MALONE, T. W.; LAUBACHER, R. J. The dawn of the e-lance economy. Harvard Business Review, n. 76, p. 144-152, 1998. 


\section{Working in a digital world; new leadership practices for the development of a digital library workforce}

MARUCA, R. F. Redesigning business. Harvard Business Review, 77, p. 19-21, 1999.

MICHAEL Dell takes on the world. American Way Magazine, n.10.01.01, p. 86-90, 93-95, 2001.

MILLS, K. L. Introduction to the electronic symposium on computersupported cooperative work. ACM Computing Surveys, n. 13, p. 105, 1999.

NANUS, B. Leading the way to renewal. Executive Excellence, n. 14, p. 17, 1997.

SANDERS, T. I. Strategic thinking and the new science : planning in the midst of chaos, complexity, and change. New York : Free Press, 1998.

SATZINGER, J. W.; GARFIELD, M. J.; NAGASUNDARAM, M. The creative process: the effects of group memory on individual idea generation. Journal of Management Information Systems, n. 15, p. 143 $160,1999$.

SENGE, P.M. Creative tension. Executive Excellence, n. 16, p. 12-13, 1999a.

SENGE, P. M. The fifth discipline: the art and practice of the learning organization. New York : Doubleday Currency, 1990.

STACEY, R. Managing the unknowable: the strategic boundaries between order and chaos. San Francisco : Jossey Bass, 1992.

STACEY, R. D. The chaos frontier: creative strategic control for business. Oxford: Butterworth-Heinemann, 1991.
STACEY, R. D. Complexity and creativity in organizations. San Francisco : Berrett-Koehler, 1996b.

STACEY, R. D. Management and the science of complexity: if organizational life is nonlinear, can business...? Research Technology Management, n. 39, p. 8-10, 1996 a.

STACEY, R. D. The science of complexity: an alternative perspective for strategic change processes. Strategic Management Journal, n. 16, p. 477-495, 1995.

STACEY, R. D. Strategic management and organisational dynamics. 2. ed. London : Financial Times Management, 1999.

STEPANEK, M. Using the net for brainstorming. Business Week, $\mathrm{n}$. 3659, p. 55-57, 1999. E-biz section.

STERNBERG, R.J.; O'HARA, L. A.; LUBART, T. I. Creativity as investment. California Management Review, n. 40, p. 8-21, Fall 1997.

SULLIVAN , M. Virtual conference: creativity in the academic libraries of the 21 st century. Disponível em: <http://library.tamu.edu/ 21stcentury/chatarchives.html Acesso em: May, 2000.

TETENBAUM, T. J. Shifting paradigms: from Newton to chaos. Organizational Dynamics, n. 26, p. 21-32, 1998.

TUCKER, K. Scenario planning. Association Management, n. 51, p. 70 $75,126,1999$

TUSHMAN, M. L.; O'REILLY, C. A. Building ambidextrous organizations: forming your own "skunk works". Health Forum Journal n. 42, p. 20-23, 1999. 